\title{
Evaluation of evaporation flux in building materials by infrared thermography
}

\author{
by M. Milazzo, N.Ludwig, V.Redaelli
}

Istituto di Fisica Generale Applicata

Università degli Studi di Milano

nicola.ludwig@unimi.it

\begin{abstract}
The presence of water inside the walls can be considered one of the most important causes of degradation in historical buildings. In particular, evaporation can give rise to salt deposits inside the superficial pores. Evaporation flux from wall surfaces can quantitatively be estimated by measuring the surface temperature since it depends in a sensitive way on the evaporation rate. The value of the surface temperature, in equilibrium conditions for all the different heat exchange contributions to the wall, depends on the evaporation rate, material's thermal conductivity as well as temperature and ventilation experimental conditions.
\end{abstract}

Several experiments have been performed on brick, plaster and stone specimens with different porosity values in the laboratory of the "Istituto di Fisica Generale Applicata" to empirically obtain correlations of temperature with evaporation rate. A climatic room with controlled environmental parameters (temperature, relative humidity, ventilation, thermal irradiation) was employed and cooling effects due to evaporation were investigated in steady conditions by a SW IR thermographic camera.

Tables for evaporation rate, water content and surface temperature values $(\Phi$, Wc, Ts) were obtained for several materials. Applicability limits of the thermographic technique for moisture detection are discussed.

\section{Introduction}

Most of the times the degradation problem in building materials is correlated to the water content inside the walls. No doubt that this latter concerns possible modifications in the material thermal and mechanical characteristics as well as ice formation. As regards surface degradation effects, however, the problem must be more exactly centered on the quantitative evaluation of the transition to vapour state for water contained inside the wall and, consequently, salt crystal depositions inside walling pores. [Massari 85. ICR 79. Rosina 98].

Growing up of crystallization nuclei is due to salt contributions from inside and it produces microfractures and flakes or powder falling from the detached most external layers.

Basically, the evaporation process from a humid surface is controlled by the difference of water contents between wall and surrounding atmosphere. More exactly, the linking function between the external relative humidity and the wall water content in equilibrium conditions depends on material porosity.

The importance of the evaporation process is well known to building conservators. On the other hand it is not easily quantifiable neither controllable.

An effective method for mapping the evaporation flux value from the wall can be obtained by means of thermography, by locating the surface zones cooled by the evaporation process. The transition from liquid to vapour states for water involves, in fact, an energy absorption of the order of $106 \mathrm{~J} / \mathrm{Kg}$ (heat of water vaporization). The cooling effect can range from a few tens to more than $10{ }^{\circ} \mathrm{C}$ depending on the characteristics of the material and the evaporation flux value. 
Measuring the temperature by a non invasive method represents the mean advantage of the thermographic technique.

By considering the atmospheric temperature, the relative humidity, the possible irradiating sources, the ventilation and heat conduction effects, we can deduce the equation for the energy balance at the wall surface and obtain a quantitative estimation of the evaporation process by measuring the surface temperature. [Redaelli 01].

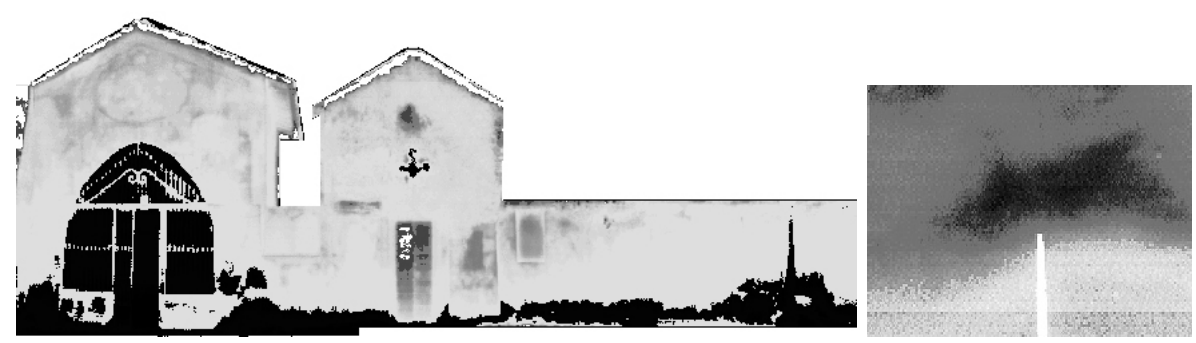

Fig. 1. Moisture detection in outdoor and indoor condition.

A) Rising damp: the dark areas in the wall of the cemetery of Erbanno (north of Italy) show the water absorption.

B) Infiltration: the dark area indicated by the stick shows the presence of a crack in the roof.

\section{Evaporation flux theory}

According the first Fick's law the water evaporation flux, $\Phi$, is proportional to the water vapour concentration gradient at the separating surface between wall and open atmosphere [Camuffo 98]:

$$
\Phi=D \frac{\Delta C}{\Delta x}
$$

where $D=0,244 \cdot 10^{-4} \mathrm{~m}^{2} / \mathrm{sec}$ is the diffusion coefficient for water in air.

The vapour concentration, $C$, can be expressed as a function of the relative humidity UR:

$$
C=C_{\text {sat }} \cdot U R
$$

where, as well known, the saturation concentration value $\mathrm{C}_{\text {sat }}$ is dependent on temperature.

We can take for $\Delta \mathrm{x}$ the value of the so called mixing layer, i.e. the layer interested by the molecular migration .

We can directly express the dependence of the evaporation flux on relative humidity values for the surface contacting air $\left(U_{\mathrm{sur}}\right)$ and the ambient $\left(\mathrm{UR}_{\mathrm{amb}}\right)$ :

$$
\Phi=\frac{D}{\Delta x} C_{s a t}\left(U R_{\text {sur }}-U R_{\text {amb }}\right)
$$

\section{Experimental procedure}

The measurement of evaporation flux as a function of water content is obtained for several samples of lime and sand plaster, brick and natural stone (Noto stone) [Milazzo 02, AIAR Congress].

The sample is imbibed with distilled water and positioned on a precision balance plate (Mettler Toledo-College: $+/-0,1 \mathrm{mg}$ ) where water evaporates in relative humidity and temperature constant conditions. 
From the variation of sample weight, $\Delta \mathrm{p}$, and the corresponding elapsed time, $\mathrm{t}$, the evaporating flux is obtained by:

$$
\Phi=\frac{\Delta p}{\Delta t \cdot \text { area }}
$$

Measurements have been performed at the same limit conditions as those which generally occur at our latitude: $30 \%, 80 \%$ for relative humidity and $10^{\circ} \mathrm{C}, 25^{\circ} \mathrm{C}$ for temperature. Neither artificial light source is used nor the solar radiation hits the samples. Ventilation is kept at minimum value $(<1 \mathrm{~m} / \mathrm{sec})$ but enough to guarantee the air circulation needed to get constant environmental quantities (UR and T).

Contemporarily with the measurement of the evaporation flux by weight control, the measurement of the surface temperature is performed by means of a short wave AVIO TVS 2000 thermographic system and, at the same time, the temperature of an identical sample, with a negligible water content, positioned by side of the wet sample is controlled to evaluate the evaporation cooling effect. In such way the correlation between temperature and flux is easily obtained.

The experimental curve giving the time dependence of the weight of a selected sample is shown in Fig.2 (black curve). Two zones with different slopes are evident . By reporting on the same figure its derivative value, the evaporative flux behaviour with time can be represented (pale curve). This latter can be considered as constant in the initial zone while it reduces progressively to zero in the final one.

Results acquire more significance if we report the evaporating flux values as a function of water weight content, $\mathrm{W}$, which is given by the ratio of water mass contained in the wet sample to the dry sample mass. For dry sample mass we assumed the final value obtained after heating the sample up to $110^{\circ} \mathrm{C}$.

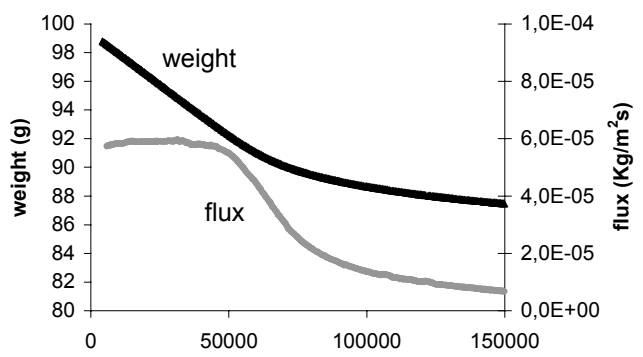

Fig. 2. Weight loøie@eec plaster sample (black line) and its derivative (grey line) over constant environmental condition $\left(\mathrm{RH}=50 \% \mathrm{~T}=25^{\circ} \mathrm{C}\right)$

$$
W(\%)=\frac{m_{w}-m_{d}}{m_{d}} \cdot 100
$$

where $m_{w}$ and $m_{d}$ are masses for wet and dry sample, respectively.

\section{Numerical evaluations}

In order to quantitatively evaluate the evaporation flux on the basis of the temperature measurement of the wall surface where the evaporation process occurs, we start from the energy balance equation in thermal equilibrium condition [Milazzo 99] :

$$
\alpha \varepsilon_{a} \sigma T_{a}^{4}-\varepsilon \sigma \mathrm{T}^{4}+h\left(T_{a}-T\right)+k^{*}\left(T_{\mathrm{int}}-T\right)+\alpha P-\Lambda_{\mathrm{ev}} \phi_{\mathrm{ev}}=0
$$

where:

$\varepsilon$ ed $\varepsilon_{\mathrm{a}}=$ sample and environment emissivity, respectively

$\alpha=$ surface absorption coefficient $=\varepsilon$

$\mathrm{P}=$ sun or lamp radiation constant

$\mathrm{T}=$ surface temperature

$\mathrm{T}_{\mathrm{a}}=$ environment temperature 
$\mathrm{T}_{\text {int }}=$ temperature at $\Delta \mathrm{x}$

$\sigma=$ Stefan-Boltzmann costant $\left(5,57 \cdot 10^{-8} \mathrm{~W} / \mathrm{m}^{2} \mathrm{~K}^{4}\right)$

$\mathrm{h}=$ convection coefficient

$\mathrm{k}^{*}=$ conduction coefficient $=\mathrm{k} / \Delta \mathrm{x}, \mathrm{k}=$ thermal conductivity

$\Lambda_{\mathrm{ev}}=$ heat of water vaporization (c. $2.4 \times 10^{6} \mathrm{~J} / \mathrm{kg}$ )

$\Phi_{\text {ev }}=$ evaporation flux $\left(\mathrm{kg} / \mathrm{m}^{2} \mathrm{~s}\right)$.

We can always consider that thermal equilibrium conditions hold during the measurements unless very rapid changes in external conditions, as for instance sudden appearance or disappearance of solar radiation, occur.

We can assume 1 for the environmental emissivity coefficient , $\varepsilon_{a}$, in equation (6) which becomes:

$$
\phi_{e v}=\frac{-\varepsilon \sigma T^{4}+\varepsilon \sigma T_{a}^{4}}{\Lambda_{e v}}+\frac{h+k^{*}}{\Lambda_{e v}} \cdot\left(T_{a}-T\right)
$$

For the numerical solution of this equation we must give a numerical value to the conductivity and convection coefficients, $k^{*}$ and $h$ (hardly to be accomplished in the working conditions), as well as the surface emissivity coefficient $\varepsilon$.

Moreover the surface temperature reading by thermocamera $(T)$ should be corrected for the real value of the emissivity coefficient $\varepsilon$ of the surface to obtain the correct value to be entered into equation (7).

It is more convenient, however, to resort to the same thermocamera for measuring the atmosphere temperature $\left(T_{a}\right)$ based on the surface temperature of an ideally dry sample in equilibrium in the same environmental conditions so that the same correcting factor applies to both temperatures in the equation (7).

Starting from the trivial position:

$$
T a^{4}-T^{4}=(T a-T)\left(T a^{3}+T a^{2} T+T a T^{2}+T^{3}\right)
$$

considering enviroment temperature values ranging from $10^{\circ} \mathrm{C}$ and $30^{\circ} \mathrm{C}$ and using for $\sigma$ e $\Lambda_{\mathrm{ev}}$ the above listed numerical values, we can write the following numerical equation:

$$
\Phi=4,2 \cdot 10^{-7} \cdot\left[\left(h+k^{*}\right)+p\right] \cdot(\mathrm{Ta}-\mathrm{T})
$$

where $p$ can be assumed from about 3,5 to 5,9 in S.I units.

We obtain in this way a remarkable simplification of the equilibrium equation since now we have a linear relationship between the lowering of the surface temperature and the evaporating flux; the angular coefficient includes the values for $h$ and $k^{*}$ which are unknown.

Evaluating under controlled conditions the evaporation flux by weighing continuously the sample with the precision balance and measuring, contemporarily, the temperature with the thermocamera, we obtained experimental behaviour like the ones shown in Fig.45 for brick, sand and stone samples.

Performing such measurements for various materials and environment conditions, the numerical value of the term $\left(h+k^{*}+p\right)$ is determined by the linear best fitting of the experimental data. So we obtain the calibration lines which can be employed in situ.

We note that for each sample we obtained the same calibration line independently of the chosen conditions for relative humidity and temperature; we recall that the experiment have been performed with a ventilation effect corresponding to an air speed less than 1 
$\mathrm{m} / \mathrm{s}$. We expect this should be a realistic approximation for indoor measurements. In order to obtain calibration lines to be used for external measurements when wind speed exceeds $1 \mathrm{~m} / \mathrm{sec}$, further laboratory experiments should be performed where more effective ventilation conditions be simulated.

The way the method applies to a real wall was tested on the plaster layer of a brick wall assembled in the laboratory (Fig.3). The plaster composition (lime and sand) was known and the evaporation rate was evaluated by infrared temperature measurements and by using the calibration line obtained for a plaster sample with the same composition. The numerical value, so obtained, for the evaporation rate is in agreement with the direct measurement obtained by weighing a sample detached from the plaster of the wall surface in the same environment conditions (Fig.5).

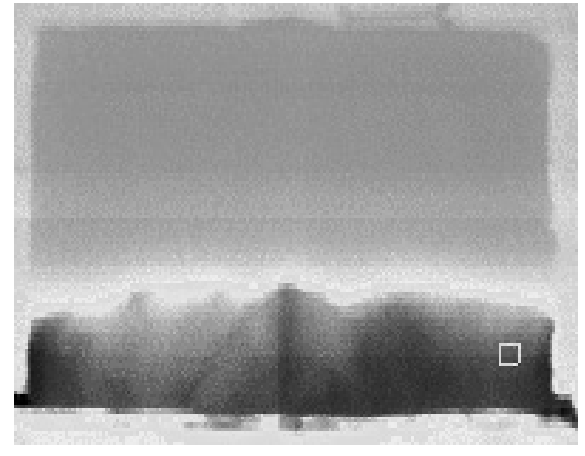

Fig.3. Rising damp in the laboratory model of wall $(43 \times 70 \times 12 \mathrm{~cm})$ in brick and mortar plaster. Square in the right corner is the area of sampling.

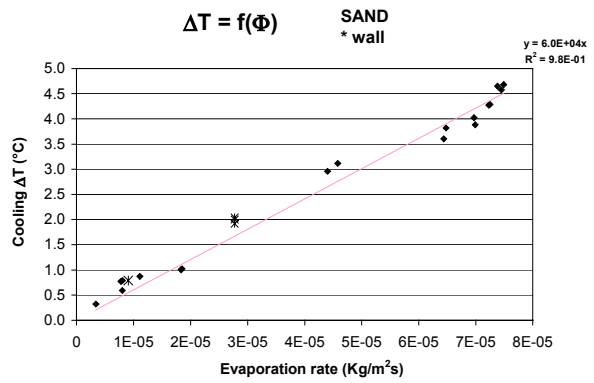

Fig. 4-5. Linear correlation between cooling and evaporation flux. On the left side Noto stone and brick samples. On the right side sand samples. The * show the measurements for the wall sample.

\section{Conclusions}

In this work we paid attention to the connection between degradation and humidity for buildings in terms of water transport to the surface. As a consequence, the evaporation flux can be considered as the most directly connected parameter with surface degradation.

On the other hand the tight correlation demonstrated for evaporation flux and surface temperature makes the thermographic method well suited to flux measurements. 


\section{BIBLIOGRAFIA}

[1] Camuffo D., 1998. Microclimate for Cultural Heritage. Elsevier.

[2] Istituto Centrale del Resaturo, 1979. Fattori di deterioramento. Dispense del corso sulla manutenzione di dipinti murali-mosaici-stucchi.

[3] Massari G. e I., 1985. Risanamento igienico dei locali umidi. Hoepli.

[4] Milazzo, M. Ludwig, N., Poldi G. 1999, Moisture detection in walls through dynamic measurement of temperature ART'99

[5] Atti 6th int. Conf. Non destructive testing and microanalysis for the diagnostics and conservation of the cultural and environmental heritage" Roma.

[6] Redaelli V., 2000/01. Misure quantitative di flussi evaporativi da materiali edilizi di interesse archeometrico mediante tecniche di termografia. Tesi di laurea in fisica. Milano

[7] Rosina, E. Ludwig, N..Rosi L. 1998, Optimal environmental condition to detect moisture in ancient buildings. Case studies in northern Italy SPIE - Thermosense XX, Orlando 188-199. 